\title{
The Evolution of IS Projects in Manufacturing Industries: The Case of Product Lifecycle Management
}

\author{
Manuel Holler \\ University of St.Gallen, Institute \\ of Information Management \\ manuel.holler@unisg.ch
}

\author{
Falk Uebernickel \\ University of St.Gallen, Institute \\ of Information Management \\ falk.uebernickel@unisg.ch
}

\author{
Walter Brenner \\ University of St.Gallen, Institute \\ of Information Management \\ walter.brenner@unisg.ch
}

\begin{abstract}
In this paper, we explore the evolution of product lifecycle management information systems projects in manufacturing industries over time. There is critical need because initiated projects routinely fail in terms of time, budget, or quality to which the academic discourse has not given adequate consideration. Therefore, we build up on an in-depth case study within the project setting of a leading European automotive supplier kicked-off in January 2016. As central results, the paper provides insights (1) how product lifecycle management information systems projects develop over time, (2) what may be underlying causes, and (3) which implications on project management may be deduced. In view of the limitations by the applied case study research strategy, we illumine the specifics of these information systems projects for scholars. For project managers, an overview on essential developments and their implications supports the successful project execution.
\end{abstract}

\section{Introduction}

The concept of product lifecycle management and its underlying information systems has been gaining importance in the scholarly (e.g., [1,2,3]) and practically relevant (e.g., $[4,5,6])$ body of literature. In essence, product lifecycle management can be conceptualized as a "business strategy of managing a company's products all the way across their lifecycles" [6:1]. Recent figures by market investigation firm Transparency Market Research [7] quantify the size of the market for product lifecycle management information systems to around 75 billion US-Dollar in the year 2022, and thus emphasize their tremendous relevance in the industrial manufacturing milieu.

Introduced across a broad front around the turn of the millennium [8], manufacturing businesses are putting their first generation of product lifecycle management information systems to the test. Given unparalleled necessities in the product realization process (market pull) and driven by powerful advancements of digital technologies (technology push), companies initiate large-scale and long-term projects to modernize their existing information systems $[6,9,10]$. Nevertheless, manufacturers are challenged by managing this transition and triggered projects regularly suffer from serious shortcomings in terms of predefined project objectives regarding time, costs, and quality in particular $[6,9,10]$ and stakeholder satisfaction in general [11].

Even though these engineering applications represent focal information systems in industrial enterprises, product lifecycle management is not an entrenched field of research in the information systems domain [3,12]. In particular, fine-grained empirical evidence regarding product lifecycle management information systems projects is mainly missing $[9,12]$. For one, the temporal progress and its implications for project management have been remarkably disregarded by literature $[9,10]$. For another, most available works study initial implementations and neglect modernization projects which gain importance within the pervasiveness of product lifecycle management in today's manufacturing business [9,10]. For scholars, such research sheds initial light on the specifics of product lifecycle management information systems projects as postulated by project management (e.g., [13]) and product lifecycle management (e.g., [9]) literature alike. For project managers, an overview on essential developments and their implications supports the successful realization of such complex projects.

Thus, this paper is interested to explore the evolution of product lifecycle management information systems projects over time. We condense the delineated motivation in the guiding research question as follows: "How do product lifecycle management information systems projects in manufacturing industries evolve over time?" We approach this study purpose on the empirical foundation of an exploratory single-case study following Yin [14]. As part of a larger empirical research endeavor on the phenomenon, 
this article characterizes essential evolution directions in product lifecycle management information systems projects in the automotive industry acquainted by the well-established framework by Batenburg et al. [15].

At first, we provide an overview on the nature of product lifecycle management, corresponding information systems projects, and related work. Next, the case study research design, surrounding case context, and data basis is outlined. We then present and discuss results in form of evolution directions. Lastly, the conclusion points out contributions, limitations, and avenues for further research.

\section{Theoretical background and related work}

\subsection{Product lifecycle management}

Cardinally, the idea of a lifecycle-oriented way of looking at things originates from the biological lifecycle of living things [8]. Nowadays, the most prominent lifecycle model for complex industrial products postulates the stages beginning-of-life, middle-of-life, and end-of-life [2,6]. At that, the product - for example an automobile or a subcomponent - is developed and produced in the beginning-of-life, distributed, utilized, maintained in the middle-of-life, and ultimately discarded in the endof-life phase [2,6]. An emerging body of literature offers a spectrum of conceptualizations of product lifecycle management accentuating its different managerial (e.g., [2]) or technological (e.g., [16]) facets. In this sense, major conceptualizations are itemized chronologically in Table 1.

Table 1. Essential conceptualizations of product lifecycle management

\begin{tabular}{|c|c|}
\hline Conceptualization & Source \\
\hline $\begin{array}{l}\text { "[...] product lifecycle management is a systematic, } \\
\text { controlled concept for managing and developing products } \\
\text { and product-related information [...]" }\end{array}$ & $\begin{array}{l}\text { Saaksvuori } \\
\text { and } \\
\text { Immonen } \\
{[4: 3]}\end{array}$ \\
\hline $\begin{array}{l}\text { "[...] product lifecycle management is a business solution } \\
\text { which aims to streamline the flow of information about the } \\
\text { product and related processes throughout the product's } \\
\text { lifecycle such that the right information in the right context } \\
\text { at the right time can be made available [...]" }\end{array}$ & $\begin{array}{l}\text { Ameri and } \\
\text { Dutta } \\
{[1: 577]}\end{array}$ \\
\hline $\begin{array}{l}\text { "[...] product lifecycle management is an integrated, } \\
\text { information-driven approach comprised of people, } \\
\text { processes/practices, and technology to all aspects of a } \\
\text { product's life, from its design through manufacture, } \\
\text { deployment and maintenance - culminating in the } \\
\text { product's removal from service and final disposal [...]" }\end{array}$ & $\begin{array}{l}\text { Grieves } \\
\text { [5:39] }\end{array}$ \\
\hline $\begin{array}{l}\text { "[...] product lifecycle management encompasses all } \\
\text { activities and disciplines that describe the product and its } \\
\text { production, operations, and disposal over the product } \\
\text { lifecycle, engineering disciplines, and supply chain [...]" }\end{array}$ & $\begin{array}{l}\text { Eigner and } \\
\text { Stelzer } \\
{[16: 37]}\end{array}$ \\
\hline $\begin{array}{l}\text { "[...] product lifecycle management is playing a "holistic" } \\
\text { role, bringing together products, services, activities, } \\
\text { processes, people, skills, ICT systems, data, knowledge, } \\
\text { techniques, practices, procedures, and standards [...]" }\end{array}$ & $\begin{array}{l}\text { Terzi et al. } \\
{[2: 364]}\end{array}$ \\
\hline $\begin{array}{l}\text { "[...] product lifecycle management is the business activity } \\
\text { of managing, in the most effective way, a company's } \\
\text { products all the way across their lifecycles [...]" }\end{array}$ & $\begin{array}{l}\text { Stark } \\
{[6: 1]}\end{array}$ \\
\hline
\end{tabular}

For this paper, we use the formulation by Stark [6] as this very current conceptualization reflects the modern, holistic understanding of product lifecycle management and is furthermore highly cited. The contemporary far-reaching scope accrued from computer-assisted product design in the 1970s and 1980 s by stepwise integration of contiguous business processes and involved stakeholders [8,16,17]. Overall, product lifecycle management needs to be understood as an intertwining set of processes, methodologies, and information and communication technology that offers to enhance effectiveness and efficiency [2].

To this end, product lifecycle management platforms integrate abundant decentral information systems [2,16]. The intelligent interplay of individual customized applications such as computer-aided design and computer-aided engineering tools rather corresponds with the idea of a product lifecycle management platform than a single "ready to use" system [2,16]. At the present day, four layer IT architectures consisting of (1) author systems, (2) team data management, (3) engineering backbone, and (4) enterprise resource planning are dominant state-of-theart $[16,17]$. In contrast, cloud-based design and manufacturing approaches [18,19] are still subject matter of research. In their seminal paper, Wu et al. [19:2] introduce this concept as "service-oriented networked product development model in which service consumers are able to configure, select, and utilize customized product realization resources and services and reconfigure manufacturing systems through IaaS, PaaS, HaaS, and SaaS in response to rapidly changing customer needs".

\subsection{Product lifecycle management IS projects}

Contrary to more traditional management forms, projects exhibit a "limited, temporary, innovative, unique, and multidisciplinary nature" [20:6]. Implying further on Laudon and Laudon [21:46] who define information systems as a "set of interrelated components that collect, process, store, and distribute information to support decision making and control in an organization", information systems projects focalize on these components [13,22]. In doing so, some authors emphasize the difference between IT and IS projects. Whereas the former is rather technically dominated, the latter is seen globally taking its environment more into account [22,23]. For this paper, we leverage the notion information systems project as we aim to view the phenomenon in its entirety. Accordingly, product lifecycle management information systems projects may be regarded as subset of information systems projects. However, attributes such as the expansive scope, complex 
interdependencies, and heavy customization make product lifecycle management projects unique beyond ordinary information systems projects [9,24]. More precisely, Hewett [25:81] stresses "cultural issues around the product engineer, a lack of standard engineering processes as a foundation for PLM, and the failings of the PLM technology itself" as distinctive features. In sum, harnessing the typology by Shenhar and Dvir [26], these projects comprise both (1) high technological uncertainty and (2) broad system scope.

Hence, the activity of project management is the "planning, organizing, directing, and controlling of company resources for a relatively short-term objective [...] to complete specific objectives and goals" [27:4]. Scientists (e.g., International Journal of Project Management and Project Management Journal) as well as practitioners (e.g., Project Management Institute and International Project Management Association) have made fruitful contributions targeting to increase project success and minimize project failure [20,28,29]. For the case at hand, the field of project dynamics (e.g., [30]) attempts to grasp temporal aspects of projects. Contingent upon the process-oriented character [2,31], product lifecycle management information systems projects are commonly accomplished by a process-oriented approach. In that context, Eigner and Stelzer [16] provide an overview on project management approaches for scientific and consulting objectives which comprise the generic phases (1) strategy development, (2) process design, (3) process implementation, and (4) process controlling.

\subsection{Related work}

For one, the cross-disciplinary field of product lifecycle management has flourished in several science fields, such as new product development and computer science [3]. For another, the area of information systems project management grew in equal measure [32]. To identify key contributions at the intersection of both, we conducted a structured literature review adopting the well-established method by Webster and Watson [33]. In a first step - for the initial literature search [33] - we browsed peer-reviewed journals and academic conferences through main databases incorporating a time frame from April 2002 to April 2017. Thereby, covering major topical constituents with manageable variation, the search string "(("product lifecycle management" OR "PLM") AND ("information systems" OR "information technology" OR “IS" OR “IT") AND ("project"))" was applied in the publication title, abstract, and key words. We limited this initial bunch of articles to those that explicitly or implicitly address the formulated research question. In a second step - for the identification of further articles [33] - a forward and backward search was accomplished. Furthermore, doubles were cleared and experts were surveyed for recommendations (books and dissertations) not included so far.

Overall, studies are rare: At a high level, Saaksvuori and Immonen [4] deal with general aspects of project management of product lifecycle management. Such a level of detail can also be found within the seminal work by Stark [6] who identifies common issues within product lifecycle management initiatives. More specifically, Hewett [25] primarily targets organizational challenges and critical issues of implementation projects. Fichman et al. [10] also immerse deeper into implementation focalizing on configurational thinking for value creation. As a last point, most time-wise aspects can be found in Bokinge and Malmqvist [9] who analyze an implementation project and reflect corresponding guidelines. Beyond these particular studies on product lifecycle management information systems projects, the rich body of literature on information systems projects (e.g., [29]) and enterprise resource planning projects (e.g., [34]) provides an insightful knowledge base.

\section{Research methodology}

\subsection{Research design and case study context}

The interest of this research is to explore how product lifecycle management information systems projects in manufacturing industries evolve over time. For this ambition, we selected an exploratory case study research design [14,35] which is based on two fundamental reasons: On the one hand, recognizing the type of research question (how? question), the control over behavioral events (no control required), and the phenomenological focus (contemporary phenomenon) [14], case study research enables us to study the complex industry-embedded phenomenon in an intense manner [36,37]. On the other hand, pivotal works on project management (e.g., $[9,10]$ ) have demonstrated its aptitude to investigate product lifecycle management information systems projects in an eligible manner. We align with Yin [14:13] and conceptualize a case study as "empirical inquiry that investigates a contemporary phenomenon within its real-life context, especially when the boundaries between phenomenon and context are not clearly evident". More specifically, we employ a holistic and single-case study design with the product lifecycle management information systems project as unit of analysis. Despite the page limitations, we strive for a stringent presentation of our elaborated research design. This seems particularly vital in consideration of 
the qualitative approach which is often charged with drawbacks [38].

Contextually, the automotive branch was selected because managing the product lifecycle is particularly demanding and critical in this domain. Since the beginning of 2015, we have been accompanying the project journey of the case organization ManuCorp. The automotive supplier from the European DACH region with more than 7,000 employees and close to three billion US-Dollar sales initiated an ample product lifecycle management project with (1) high technological uncertainty and (2) broad system scope [26]. We opt for a single-case study because of (1) the complex nature of product lifecycle management projects $[9,24,25],(2)$ the case's revelatory character [14] through the possibility for long-term and unrestricted access, and (3) its typicality [14] as traditional fabrication business managing its modernization.

In order to cope with the context dependence of case study research [14], we outline substantial characteristics of the case setting at ManuCorp. Founded in the 1930s, the firm nowadays operates as a subsidiary of a leading multinational. Around the 1990s the company become part of its automotive business area within an M\&A transaction. In the first two decades rather under a financial than strategic roof, ManuCorp and the multinational increasingly aim for synergies. In terms of core business, ManuCorp is specialized in designing and producing mechanical and mechatronic components and systems for major automotive players. For that, the company is organized on a global scale with R\&D locations in Europe and sales and assembly centers in Asia and North America. Having installed a product data management and enterprise resource planning system in the late 1990s which was incrementally further developed, the prime rationale for the project was reasoned in the rapid growth of revenues and rising product complexity. Hence, product lifecycle management processes and information systems had to be re-evaluated and adapted. In this context, Figure 1 demonstrates the timeline of ManuCorp's project including major project phases and accomplished activities. We studied the project as far as April 2017 as major adaptions have been completed and the project has reached linear progress.

Supported by a Swiss technology consultancy (ConsultCorp), the project is realized in a bottom-up and process-oriented fashion [2,31]. After a brief scoping phase in 2015, the actual project started in early 2016 and is planned to be finished by the end of 2017, comprising three main phases: In stage I, an analysis of the current processes and information systems, development of a basic concept, and cost- benefit analysis represented the main elements. Subsequently, in stage II, the design of a target concept with detailed requirements including its extensive evaluation, and finally, in stage III, the concrete system implementation and roll-out acted as core constituents.



Figure 1. Timeline of ManuCorp's product lifecycle management IS project

Whereas stage I is system-neutral, stage II and III is already system-specific. The project is set up with a core project team of ten members encompassing specialists with relevant managing, operating, and supporting departments involved, rather regularly in workshops or more temporary in milestone meetings.

\subsection{Data collection and analysis}

Integrating different viewpoints from research at ManuCorp, this paper is grounded on primary and secondary data [39]. For data collection and analysis, we leveraged a range of interlinked sources of evidence and techniques [14,35]. For evidence collection, semi-structured interviews [14] and focus groups [40] were harnessed to examine the progress of the product lifecycle management information systems project. With regard to the sampling strategy, informants held key responsibilities in the project (purposeful sampling, [41]). In detail, seven IT roles (e.g., Chief Information Officer), eleven technical roles (e.g., Head of Manufacturing Engineering), and five management roles (e.g., Head of Innovation Management) from ManuCorp as well as its parent company and ConsultCorp were considered to collect rich and diverse evidence. An iteratively refined interview questionnaire [42,43] and workshop guideline [40] instructed the data collection. As additional sources of evidence [14] we could access the complete project documentation and accomplish observations within the frame of regular visits of the project site. Beyond, we also exploited archival records [14] to augment and triangulate our data sets. Using these resources, we were able to study the project from both an (1) individual and (2) organizational 
perspective [14]. To summarize, Table 2 outlines details of analyzed sources of evidence. For the sake of a compelling processing, conversations were taped up, transcribed, and consolidated in a database $[44,45]$.

$\begin{aligned} & \text { Table 2. Details of analyzed sources of } \\
& \text { evidence }\end{aligned}$
\begin{tabular}{|l|l|}
\hline Source of evidence & Specification \\
\hline $\begin{array}{l}\text { Interviews/ } \\
\text { focus groups }\end{array}$ & $\begin{array}{l}\text { Two resumptive interviews (February 2017)* and } \\
21 \text { intermediate interviews (May 2015 - February } \\
2017)^{* *}, \text { four intermediate focus groups (May } \\
2015-\text { April 2017)* }\end{array}$ \\
\hline \multirow{5}{*}{ Documentations } & $\begin{array}{l}\text { Complete project documentation compiled by } \\
\text { ConsultCorp, e.g., project plans, roadmaps, } \\
\text { specifications, deliverables, status and cost } \\
\text { reportings* }\end{array}$ \\
\hline Observations & $\begin{array}{l}\text { Continuous project companionship (May 2015 - } \\
\text { April 2017) with an average of two days per week } \\
\text { at project site including participation in major } \\
\text { meetings* }\end{array}$ \\
\hline \multirow{2}{*}{ Archival records } & $\begin{array}{l}\text { Comprehensive documentation of product } \\
\text { lifecycle management history of ManuCorp, e.g., } \\
\text { process and system documentations, implemented } \\
\text { modifications** }\end{array}$ \\
\hline * Primary data, ** Secondary data \\
\hline
\end{tabular}

For evidence analysis, we utilized qualitative coding techniques $[46,47,48]$. We did so because such practices are adequate for the novel, uncharted phenomenon and our exploratory research strategy at hand $[46,47,48]$. Furthermore, this kind of analyses enabled us to generate insights valuable for scholars and managers alike [48]. Not least, the advantages of grounded analyses are increasingly recognized in the information systems domain [49]. From a processual perspective, we broke up the data in the (1) open coding, created initial relationships in the (2) axial coding, and reorganized them in the (3) selective coding stage [46,47]. To empower efficiency and effectiveness of coding sequences and to promote rigor, analysis software NVIVO 10 was availed.

Thereby, the well-established product lifecycle management framework [15] informed our coding processes. More precisely, the framework which is rooted in the IT business alignment [50] comprises the dimensions (1) strategy and policy, (2) management and control, (3) organization and processes, (4) people and culture, and (5) information technology. We selected this analysis framework because of three rationales: First, the framework represents the product lifecycle management project in an overarching manner which goes in line with the goal of this paper. Hence, it enables us to examine technical and nontechnical as well as static and dynamic aspects. Second, the framework is anchored in theory and validated through empirical evidence [15] and thus, contributes to guy our study in existing research. Ultimately, the structure affords to go more into detail than rather rough project management frameworks, for example proposed by Kerzner [27].

\section{Case study results}

In the case study, we identified evidence for the evolution of product lifecycle management information systems projects in manufacturing industries. In aggregate form, Table 3 visualizes ManuCorp's project dynamics from January 2016 to April 2017 along the introduced framework [15] and provides selected supporting literature for each evolution direction.

\subsection{Strategy and policy}

The temporal progress of the project entailed remarkable changes regarding the first analysis dimension, aspects of strategy and policy. Initiated to renew the extant product data management system to enable a more competitive product design, the project objective evolved to the implementation of product lifecycle management as concept: "Within the first year, we recognized that a pure system replacement is not enough, instead we conceived the need to introduce novel topics and product lifecycle management as holistic management approach." (Head of IT Engineering, ManuCorp, February 2017). This shift from a pure ICT-centric understanding to an appreciation as business strategy was triggered by internal as well as external drivers: "By visits of technology fairs and intensive exchange with our operating departments, we learned how product lifecycle management is understood today and what real user needs are." (Head of IT Engineering, ManuCorp, February 2017).

Furthermore, an augmented involvement of ManuCorp's parent company seeking economies of scale shaped the scope in the course of the project duration. Thus, the role of the project made progress from the development of an autonomous strategy for ManuCorp to assessing possibilities for a scalable strategy for other business units of the parent company in the style of a lighthouse project: "Beside my role as IT project lead at our business unit, I took on a role in our automotive business area where we strive to scale our project outcomes. For one, this has positive effects for our corporation, for another some decelerating and compromising effects through necessary alignment and additional requirements." (Chief Information Officer, ManuCorp, February 2017).

\subsection{Management and control}

The project's chronological sequence also had farreaching impact on the second analysis dimension, issues of management and control. Driven by Chief Information Officer and Head of IT Engineering at the very start, increasingly top management attention 
through Chief Executive Officer and Head of Operations swapped over as they recognized the strategic and critical role of product lifecycle management for ManuCorp's future product and service business: "For a few months, we regularly host steering committees to inform the executive board and provide them the opportunity to shape strategic directions." (Core Project Team Member, ManuCorp, November 2016). Complementary to this novel control mode, a decentralization of project management became nascent as well. The number of involved people imposing requirements has been rising constantly since the project beginning: "More people want to be informed, want to influence decisions, and want to shape the project." (Consultant, ConsultCorp, November 2016). This resulted in a core team extension with further representatives.

Aspects that did not affect the project in a direct way, but rather shaped it indirectly, are influences through МапиCorp's customer, supplier, and partner ecosystem. In addition to the initial narrowly drawn internal focus, the project quickly stretched towards further stakeholders beyond the enterprise boundaries. In the heavy interconnected ecosystem of the automotive industry, customers (original equipment manufacturers) on the demand side and suppliers (part and machine suppliers) on the supply side were factored in: "Increasingly we need to seek bilateral exchange with our partners, but also with standardization organizations for industry overarching requirements." (Core Project Team Member, ManuCorp, November 2016). These stakeholders impose new and modify extant requirements.

Table 3. Evolution of ManuCorp's product lifecycle management IS project

\begin{tabular}{|c|c|c|c|c|c|}
\hline $\begin{array}{l}\text { Temporal } \\
\text { progress }\end{array}$ & $\begin{array}{l}\text { Strategy and } \\
\text { policy }\end{array}$ & $\begin{array}{l}\text { Management and } \\
\text { control }\end{array}$ & $\begin{array}{l}\text { Organization and } \\
\text { processes }\end{array}$ & $\begin{array}{l}\text { People and } \\
\text { culture }\end{array}$ & $\begin{array}{l}\text { Information } \\
\text { technology }\end{array}$ \\
\hline $\begin{array}{l}\text { Initial product } \\
\text { lifecycle management } \\
\text { IS project (January } \\
2016 \text { ) }\end{array}$ & $\begin{array}{l}\text { Objective: } \\
\text { Renewal of product } \\
\text { data management } \\
\text { system } \\
\text { Scope: } \\
\text { Autonomous strategy } \\
\text { for ManuCorp }\end{array}$ & $\begin{array}{l}\text { Steering: } \\
\text { Chief Information } \\
\text { Officer and Head of } \\
\text { IT Engineering with } \\
\text { core project team }\end{array}$ & $\begin{array}{l}\text { Value chain: } \\
\text { Product development } \\
\text { and manufacturing } \\
\text { engineering processes }\end{array}$ & $\begin{array}{l}\text { Perception: } \\
\text { Niche project with } \\
\text { supporting character } \\
\text { Awareness: } \\
\text { Little awareness on } \\
\text { product lifecycle } \\
\text { management }\end{array}$ & $\begin{array}{l}\text { IT architecture: } \\
\text { Incremental further } \\
\text { development of IT } \\
\text { architecture }\end{array}$ \\
\hline $\begin{array}{l}\text { Evolved product } \\
\text { lifecycle management } \\
\text { IS project (April } \\
\text { 2017) }\end{array}$ & $\begin{array}{l}\text { Objective: } \\
\text { Implementation of } \\
\text { product lifecycle } \\
\text { management as } \\
\text { concept } \\
\text { Scope: } \\
\text { Scalable strategy for } \\
\text { parent company }\end{array}$ & $\begin{array}{l}\text { Steering: } \\
\text { Chief Executive } \\
\text { Officer and Head of } \\
\text { Operations with } \\
\text { extended core project } \\
\text { team, influences } \\
\text { through ecosystem }\end{array}$ & $\begin{array}{l}\text { Value chain: } \\
\text { End-to-end value } \\
\text { chain with direct } \\
\text { integrations and } \\
\text { indirect allowances, } \\
\text { engineering } \\
\text { disciplines integration }\end{array}$ & $\begin{array}{l}\text { Perception: } \\
\text { Central project } \\
\text { attracting attention } \\
\text { Awareness: } \\
\text { Awareness on product } \\
\text { lifecycle management } \\
\text { as concept through } \\
\text { learning process }\end{array}$ & $\begin{array}{l}\text { IT architecture: } \\
\text { Rethinking of IT } \\
\text { architecture (macro } \\
\text { level), introduction of } \\
\text { novel product } \\
\text { realization approaches } \\
\text { (micro level) }\end{array}$ \\
\hline $\begin{array}{l}\text { Supporting literature } \\
\text { (selected) }\end{array}$ & $\begin{array}{l}\text { Terzi et al. [2]; Stark } \\
\text { [6]; Abramovici and } \\
\text { Göbel [51] }\end{array}$ & $\begin{array}{l}\text { Fichman et al. [10]; } \\
\text { Hewett [25]; Garetti et } \\
\text { al. [52] }\end{array}$ & $\begin{array}{l}\text { Terzi et al. [2]; Eigner } \\
\text { and Stelzer [16]; } \\
\text { Eigner and Roubanov } \\
{[17]}\end{array}$ & $\begin{array}{l}\text { David and Rowe [3]; } \\
\text { Hewett [25]; Garetti } \\
\text { et al. [52] }\end{array}$ & $\begin{array}{l}\text { Eigner and Stelzer } \\
\text { [16]; Eigner and } \\
\text { Roubanov [17]; } \\
\text { Bergsjö [53] }\end{array}$ \\
\hline
\end{tabular}

\subsection{Organization and processes}

By far, the most vigorous changes originated in the third analysis dimension referring to aspects of organization and processes. Primarily started to enhance key processes of product development and manufacturing engineering, ManuCorp increasingly discovered the necessity to involve flanking value chain processes. On the one hand, additional affected functions such as requirements engineering were directly integrated: "Initially, the project was triggered by long-term pain points from series development. Step-by-step we discovered the tight relationships and realized that we need a more global end-to-end perspective." (Core Project Team Member, ManuCorp, September 2016). On the other hand, more distant functions like procurement were considered in an indirect manner. As other modernization projects were ongoing in parallel, these functions were allowed by interfaces: "Ideally such a project would cover the whole lifecycle, but operatively projects are divided in more manageable subsets. We carefully selected which value chain elements are in scope, out of scope, or affected." (Consultant, ConsultCorp, November 2016).

A nameable evolution is related to engineering disciplines. Over time, the project scope opened from mechanical development processes for physical components to electrics, electronics, and software engineering processes for mechatronic systems. Originally launched to deal better with the complexity, variety, and quantity of the product realization process of mere physical components, ManuCorp realized the relevance of digital components (sensors, embedded systems, and actuators) for innovative product functions: 
"Most dominantly, this radical further development manifested in the project title. The project was renamed from "product lifecycle management strategy" to "systems lifecycle management strategy"." (Head of IT Engineering, ManuCorp, February 2017). In essence, this shift and enlargement of scope doubled the number of involved engineers and their information systems.

\subsection{People and culture}

The temporal progress of the project also unveiled dynamics related to people and culture, the fourth analysis dimension. Kicked-off in 2015 as niche project with a rather supporting character, the product lifecycle management information systems project gradually evolved to a central project attracting attention throughout the whole firm. Moreover, upon the company-wide extent and impact, the product lifecycle management project became one of the essential digitization activities at ManuCorp: "In general, the awareness for the project has been growing strongly. More people speak and discuss about the project. Now it is a common conversational topic on the corridors here." (Head of IT Engineering, ManuCorp, February 2017). In that regard, an inspirational talk on the technological possibilities for a broad public by a scholar in the summer of 2016 can be regarded as a fostering event. Even beyond the enterprise boundaries the project became well-known in the parent company which has led to an augmented interest as described in the preceding paragraph.

Beyond the perception of the project, the awareness of product lifecycle management itself by the organization showed a highly dynamic behavior. An intensive learning process became perceivable within the project accomplishment. Through intense engagement with the topic in regular workshops, project management staff, but also research and development- and product realization-related functions discovered the manifold and complex faces of product lifecycle management: "In particular, the apprehension of product lifecycle management as concept, not as application or IT platform was one of our major learnings." (Head of IT Engineering, ManuCorp, February 2017). Overall, people- and culture-related aspects exhibited a substantial and profound evolution.

\subsection{Information technology}

The fifth analysis dimension copes with chronological issues in terms of information technology. At a macro level, in accordance with the early project scope, the project targeted a more incremental further development of the existing IT architecture. In line with the evolving, increasingly disruptive project character, a more fundamental rethinking of the IT architecture found its way into the project: "By now, we discuss completely new arrangements of the IT architecture layers and components including cloud computing approaches." (Project Manager IT Engineering, ManuCorp, November 2016). In general, upon the complexity more functionality is assigned to layers more close to the authors systems. Furthermore, another major challenge is the composition of a suitable IT architecture for the systems lifecycle management approach for developing mechatronic systems.

At the other information technology spectrum, at a micro level, the necessity to introduce novel product realization approaches like model-based systems engineering occurred over time. The technology to support product realization developed more distinctly than expected by ManuCorp at the project kick-off: "Increasingly, we conduct educational workshops with the product lifecycle management state-of-the-art such as model-based systems engineering or closed-loop product lifecycle management enabled by intelligent products in the context of Industry 4.0." (Consultant, ConsultCorp, November 2016). In closing, the weightiness of these IT-related changes manifested in the recruitment of two additional IT engineering specialists starting their full-time activities in the spring of 2017. Whereas the first expert aims at creating an overarching architectural picture, the second specialist strives to support the introduction of more specific technologies.

\section{Discussion}

\subsection{General discussion of case study results}

First, we commence with a general discussion including a quality assessment and embedding in literature. Our underlying philosophical assumption is an interpretivist epistemology. In contrast to practices for positivist case studies [54], Walsham [55,56] as well as Klein and Myers [57] introduce guidelines for interpretive studies. Ranging from concept to publication, we exerted these principles relating to (1) carrying out fieldwork, (2) theory and data analysis, and (3) constructing and justifying a contribution [56] to the best of our knowledge. In addition, Guba and Lincoln [58] discuss criteria of trustworthiness for interpretive studies. We aimed to enhance credibility, dependability, and confirmability by intense engagement, opposite reasoning with further scholars and practitioners, and provision of raw data. With regard to transferability, we believe that with 
ManuCorp there is a typical case similar to other manufacturing enterprises at hand. Yet, generalizing is limited in single-case studies and influences by the parent company and the powerful automotive ecosystem should be mentioned at this juncture which brought in additional dynamics. With a view to potential biases of our direct involvement we note that our role had a rather supporting than directing character and we generally aimed for mindful research.

Next, debating content-wise on the findings, profound dynamics of product lifecycle information systems projects became visible. Moreover, in all dimensions of the analysis framework, major adaptions over the project progression came to the fore. Recalling the aim for stringent project management by ManuCorp, this appears indeed surprisingly. Correlating this central finding with existing literature from information systems project management (e.g., [13]) in general and the introduced product lifecycle management (e.g., [6,9]) in particular, these dynamics have been indicated by previous research, but not described in detail. Comparing the evolution directions in terms of their impact on posed project objectives, the value chain integration - in particular the integration of engineering disciplines - had the greatest influence. Accordingly, the impactful shift from product to systems lifecycle management for increasingly mechatronic and digitized products [59] may be paid the most attention. Examining more detailed the temporal sequence of the project, the scope steadily widened over time, yet the intensity varied wavelike. Started with strong intensity during the interviews and workshops for the current state identification, the following stages were characterized with low intensity for scoping and high intensity for completing novel scopes. Furthermore, whereas it seems obvious that companies which are implementing product lifecycle management for the first time are confronted with challenges, it remains conspicuous that businesses with more experience also undergo severe challenges. Ultimately, juxtaposing this product lifecycle management project with the introduced traditional information systems projects (e.g., [29]) and enterprise resource planning projects (e.g., [34]), some similarities such as the important role of (top) management can be detected. In contrast, the necessity for customization to meet the lacking engineering standards represents an example for differentiation which both go in line with literature $[12,25]$.

\subsection{Sensemaking of IS project evolutions}

Second, having discussed the manifold facets of the project evolutions, sensemaking of the underlying reasons seems worthwhile. Investigating the reasons of these profound dynamics, there is recurring evidence that product lifecycle management as concept with its far-reaching outreach is not fully understood although its character has been highlighted by research and practice for a considerable time: For example, Eigner and Stelzer [16] sketched the solution space comprising the dimensions (1) product lifecycle, (2) supply chain, and (3) engineering domains. Later on, Terzi et al. [2] nominated product lifecycle management as interlinked set of processes, methodologies, and information and communication technology. Moreover, David and Rowe [3] emphasized its managerial character. This misjudgment has led to serious deficits regarding agreed project goals for ManuCorp and may be a conceivable situation for other traditional fabrication businesses. Thus, the severe project dynamics may uncover the paradoxical nature of product lifecycle management information systems projects: Although the extent is principally known, the project endeavor starts with a compact scope, commonly triggered by a specific pain point. Then, the project dilatation emerges step-wise in parallel with an organizational learning process. Whereas some dimensions of product lifecycle management are well-known, others seem to be more underestimated. The case indicated that technical dimensions tendentially seem to be better understood than organizational dimensions which is also reported by previous studies (e.g., [25]). Overall, such pervasive dynamics seem not unexpected as such projects are initiated seldom. Thus, not much knowledge is available within the organization.

\subsection{Implications on IS project management}

Finally, in consequence this specific character has profound implications on the design of product lifecycle management information systems projects in manufacturing industries. Based on our findings, we argue that it is necessary and worthwhile to consider the dynamics in project management. Thus, existing methods and practices (e.g., [9]) need to be refined. Therefore, adopting a project lifecycle perspective, evolution-driven implications in particular refer to (1) project preparation and (2) project execution: First, we propose that project resources may be increasingly allocated from project operations to planning stages. We do so because quality management research (e.g., [27]) has shown that project change costs rise exceedingly with proceeding project lifecycle. Moreover, with reference to the uncovered limited understanding of product lifecycle management, these resources may be particularly assigned to accelerate the organizational learning process. So, for example a maturity assessment and advanced training before 
project initiation can support the specification and validation of the forthcoming project. Specifically, ManuCorp respectively its parent company targets a business area-overarching maturity assessment and a periodic forum on product lifecycle management topics. Second, complementary to these preparatory activities, we suggest that at an increasing rate elements from agile project management (e.g., [60]) may be incorporated. Upon the complex, evolving nature of product lifecycle management information systems projects, agile approaches seem well qualified as they are explicitly designed to react to change [60]. So, elements such as continuous feedback loops can assist a successful project operation. In detail, ManuCorp has partitioned the remaining project time in shorter cycles to gain in agility. This leads over to the established discussion of plan-based versus agile project management [60]. Our case study shows evidence that these projects can benefit from a consideration of both approaches offering immediate value and high assurance alike. Beyond these managerial implications, academic research should increasingly look after these emerging projects. In particular, the complex real-world character should be addressed.

\section{Conclusion}

The paper at hand strives to study the evolution of product lifecycle management information systems projects over time. We do so because the far-reaching complexity of such projects poses challenges on producers to which the academic discourse has not given sufficient consideration. Grounded on a case study approach, we retrospectively captured the evolution of product lifecycle management information systems projects utilizing an established analysis framework. Going back to the posed research question, we can conclude that these information systems projects show a highly dynamic character.

For research, we offer three main contributions: First, to the best of our judgement this manuscript is the first to examine the chronological sequence of such projects in an ample way. Thus, by elaborating temporal aspects, we shed initial light on the specifics of these projects as claimed by literature (e.g., $[9,13])$. Second, we provide a connecting factor for other scholars [33]. Grounded on the preliminary findings as starting point, we would like to animate researchers continuing and extending this aspiring research field towards theoretical contributions. Finally, as truly interdisciplinary academic domain [33,61], we connect the domain of information systems with the research community of project management and product lifecycle management.
For practice in today's demanding manufacturing industries, the case study provides a valuable overview of real-world insights and implications for project managers charged with similar tasks in the digital age. As the success of these information systems projects becomes a pivotal factor for the future prosperity of producers, this knowledge holds the potential to support IT executives overcoming the multidimensional challenges and increasing the success rate.

Nevertheless, we acknowledge that our approach is exposed to weaknesses, conceptually, empirically, and analytically: First, conceptually, the exploratory approach cannot provide completeness, the interpretive approach is formed by social construction. Second, empirically, the single-case study offers extensive description, yet is paralleled by limited generalizability. Ultimately, analytically, upon the heterogeneity of involved sources of evidence, the processing procedures encompassed some simplifications (e.g., summary report of meetings instead of full transcript) for the sake of operability.

As an outlook, accomplishing further case studies can endorse or disconfirm the identified dynamics and furthermore enhance the generalizability of the findings (cross-case analysis, Yin [14]). In addition, the identification of specific factors influencing project success or project failure can make an appreciated contribution as well. Selected of these issues will be the content of our future research works, yet we hope that this research also will fuel further scholars.

\section{References}

[1] Ameri, F., and D. Dutta, "Product Lifecycle Management: Closing the Knowledge Loops", Computer-Aided Design \& Applications 2, 5 (2005), pp. 577-590.

[2] Terzi, S., A. Bouras, D. Dutta, M. Garetti, and D. Kiritsis, "Product lifecycle management - From its history to its new role", International Journal of Product Lifecycle Management 4, 4 (2010), pp. 360-389. [3] David, M., and F. Rowe, "Le management des systèmes PLM (product lifecycle management): Un agenda de recherche", Journal of Decision Systems 24, 3 (2015), pp. 273-297.

[4] Saaksvuori, A., and A. Immonen, Product Lifecycle Management, Springer, Berlin/Heidelberg, 2002.

[5] Grieves, M., Product Lifecycle Management: Driving the Next Generation of Lean Thinking, McGraw-Hill, New York, 2006.

[6] Stark, J., Product Lifecycle Management: 21st Century Paradigm for Product Realisation, Springer, London, 2015.

[7] Transparency Market Research, Product Lifecycle Management (PLM) Market - Global Industry Analysis, Size, Share, Growth, Trends and Forecast (2015-2022), 2015.

[8] Cao, H., and P. Folan, "Product life cycle: the evolution of a paradigm and literature review from 1950-2009", Production Planning \& Control 23, 8 (2012), pp. 641-662.

[9] Bokinge, M., and J. Malmqvist, "PLM implementation guidelines relevance and application in practice: a discussion of findings from a retrospective case study", International Journal of Product Lifecycle Management 6, 1 (2012), pp. 79-98.

[10] Fichman, R. G., S. Nambisan, and M. Halpern, "Configurational Thinking and Value Creation from Digital Innovation: The Case of Product Lifecycle Management Implementation", in Rowe, F., and D. Te'eni (eds.), "Innovation and IT in an International Context: R\&D Strategy and Operations", Palgrave Macmillan, Basingstoke, 2013, pp. 115-139. 
[11] Wateridge, J., "How can IS/IT projects be measured for success?", International Journal of Project Management 16, 1 (1998), pp. 59-63. [12] Merminod, V., and F. Rowe, "How does PLM technology support knowledge transfer and translation in new product development? Transparency and boundary spanners in an international context", Information and Organization 22, 4 (2012), pp. 295-322.

[13] Cadle, J., and D. Yeates, Project Management for Information Systems, Pearson Education, Harlow, 2008.

[14] Yin, R. K., Case Study Research - Design and Methods, Sage, London, 2003.

[15] Batenburg, R., R. W. Helms, and J. Versendaal, "PLM roadmap: stepwise PLM implementation based on the concepts of maturity and alignment", International Journal of Product Lifecycle Management 1, 4 (2006), pp. 333-351.

[16] Eigner, M., and R. Stelzer, Product Lifecycle Management - Ein Leitfaden für Product Development und Life Cycle Management, Springer, Berlin/Heidelberg, 2008.

[17] Eigner, M., and D. Roubanov, Modellbasierte virtuelle Produktentwicklung, Springer, Berlin/Heidelberg, 2014.

[18] Lehmhus, D., T. Wuest, S. Wellsandt, S. Bosse, T. Kaihara, K. D. Thoben, and M. Busse, "Cloud-Based Automated Design and Additive Manufacturing: A Usage Data-Enabled Paradigm Shift", Sensors 15, 12 (2015), pp. 32079-32122.

[19] Wu, D., D. W. Rosen, and D. Schaefer, "Cloud-Based Design and Manufacturing: Status and Promise", in Schaefer, D. (ed.), "Cloud-Based Design and Manufacturing (CBDM)", Springer, Cham, 2014, pp. 1-24. [20] Ika, L. A., "Project Success as a Topic in Project Management Journals", Project Management Journal 40, 4 (2009), pp. 6-19.

[21] Laudon, K. C., and J. P. Laudon, Management Information Systems - Managing the Digital Firm, Pearson, Upper Saddle River, 2009.

[22] Atkinson, R., "Project Management: Cost, Time and Quality, Two Best Guesses and a Phenomenon, its Time to Accept other Success Criteria", International Journal of Project Management 17, 6 (1999), pp. 337-342.

[23] Hartman, F., and R. A. Ashrafi, "Project Management in the Information Systems and Information Technologies Industries", Project Management Journal 33, 3 (2002), pp. 5-15.

[24] Subrahmanian, E., S. Rachuri, S. J. Fenves, S. Foufou, and R. D. Sriram, "Product lifecycle management support: a challenge in supporting product design and manufacturing in a networked economy", International Journal of Product Lifecycle Management 1, 1 (2005), pp. 4-25.

[25] Hewett, A., "Product Lifecycle Management (PLM): Critical Issues and Challenges in Implementation", in Nambisan, S. (ed.), "Information Technology and Product Development", Springer, Berlin/Heidelberg, 2010, pp. 81-104.

[26] Shenhar, A. J., and D. Dvir, "Towards a typological theory of project management”, Research Policy 25, 4 (1996), pp. 607-632.

[27] Kerzner, H., Project Management: A Systems Approach to Planning, Scheduling, and Controlling, John Wiley \& Sons, New Jersey, 2013. [28] Pinto, J. K., and D. P. Slevin, "Critical Success Factors Across the Project Life Cycle", Project Management Journal 19, 3 (1988), pp. 67-75. [29] Yeo, K. T., "Critical failure factors in information system projects", International Journal of Project Management 20, 3 (2002), pp. 241-246. [30] Lyneis, J. M., and D. N. Ford, "System dynamics applied to project management: a survey, assessment, and directions for future research", System Dynamics Review 23, 2/3 (2007), pp. 157-189.

[31] Scheer, A.-W., M. Boczanski, M. Muth, W.-G. Schmitz, and U. Segelbacher, Prozessorientiertes Product Lifecycle Management,

Springer, Berlin/Heidelberg, 2006

[32] Pankratz, O., and D. Basten, "Eliminating Failure by Learning from it - Systematic Review of IS Project Failure", Proceedings of the 34th International Conference on Information Systems (2013), Milan, Italy. [33] Webster, J., and R. Watson, "Analyzing the Past to Prepare for the Future: Writing a Literature Review”, MIS Quarterly 26, 2 (2002), pp. xiii-xxiii.

[34] Akkermans, H., and K. van Helden, "Vicious and virtuous cycles in ERP implementation: a case study of interrelations between critical success factors", European Journal of Information Systems 11, 1 (2002), pp. 35-46.

[35] Eisenhardt, K. M., "Building Theories from Case Study Research", Academy of Management Review 14, 4 (1989), pp. 532-550.
[36] Benbasat, I., D. K. Goldstein, and M. Mead, "The Case Research Strategy in Studies of Information Systems”, MIS Quarterly 11, 3 (1987), pp. 369-386.

[37] Sarker, S., X. Xiao, and T. Beaulieu, "Qualitative Studies in Information Systems: A Critical Review and Some Guiding Principles", MIS Quarterly 37, 4 (2013), pp. iii-xviii.

[38] Myers, M. D., Qualitative Research In Business And Management, Sage, Thousand Oaks, 2013.

[39] Heaton, J., Reworking Qualitative Data, Sage, Thousand Oaks, 2004

[40] Morgan, D. L., Focus Groups as Qualitative Research, Sage,

Newbury Park, 1988.

[41] Coyne, I. T., "Sampling in qualitative research. Purposeful and theoretical sampling; merging or clear boundaries?", Journal of Advanced Nursing 26, 3 (1997), pp. 623-630.

[42] Rubin, H. J., and I. S. Rubin, Qualitative Interviewing: The Art of Hearing Data, Sage, Thousand Oaks, 2004.

[43] Schultze, U., and M. Avital, "Designing Interviews to Generate Rich Data for Information Systems Research", Information and Organization 21, 1 (2011), pp. 1-16.

[44] Alam, I.. "Fieldwork and Data Collection in Qualitative Marketing Research", Qualitative Market Research: An International Journal 8, 1 (2005), pp. 97-112.

[45] Sinkovics, R., E. Penz, and P. N. Ghauri, "Analysing Textual Data in International Marketing Research", Qualitative Market Research: An International Journal 8, 1 (2005), pp. 9-38.

[46] Strauss, A. L., and J. M. Corbin, Basics of qualitative research: Grounded theory procedures and techniques, Sage, Newbury Park, 1990. [47] Strauss, A. L., and J. M. Corbin, Grounded Theory in Practice, Sage, Thousand Oaks, 1997.

[48] Charmaz, K. C., Constructing Grounded Theory: A Practical Guide through Qualitative Analysis, Sage, London, 2006.

[49] Wiesche, M., M. C. Jurisch, P. Yetton, and H. Krcmar, "Grounded Theory Methodology in Information Systems Research", MIS Quarterly 41, 3 (2017), pp. 685-701.

[50] Henderson, J. C., and N. Venkatraman, "Strategic alignment: Leveraging information technology for transforming organizations", IBM Systems Journal 32, 1 (1993), pp. 472-484.

[51] Abramovici, M., and J. C. Göbel, "Decision Support Framework for PLM Harmonization Projects within Industrial Companies", in Rivest, L. A. Bouras, and B. Louhichi (eds.), "Product Lifecycle Management Towards Knowledge-Rich Enterprises", Springer, Berlin/Heidelberg, 2011, pp. 535-546.

[52] Garetti, M., S. Terzi, N. Bertacci, and M. Brianza, "Organisational change and knowledge management in PLM implementation", International Journal of Product Lifecycle Management 1, 1 (2005), pp. 43-51.

[53] Bergsjö, D., "Flexible PLM architecture as an enabler for multidisciplinary engineering", International Journal of Product Lifecycle Management 7, 4 (2014), pp. 249-265.

[54] Dubé, L., and G. Paré, "Rigor in Information Systems Positivist Case Research: Current Practices, Trends, and Recommendations", MIS Quarterly 27, 4 (2003), pp. 597-635.

[55] Walsham, G., "Interpretive Case Studies in IS Research: Nature and Method", European Journal of Information Systems 4, 2 (1995), pp. 74-81.

[56] Walsham, G., "Doing Interpretive Research", European Journal of Information Systems 15, 3 (2006), pp. 320-330.

[57] Klein, H. K., and M. D. Myers, "A Set of Principles for Conducting and Evaluating Interpretive Field Studies in Information Systems", MIS Quarterly 23, 1 (1999), pp. 67-94.

[58] Guba, E. G., and Y. S. Lincoln, Fourth Generation Evaluation, Sage, Newbury Park, 1989.

[59] Yoo, Y., O. Henfridsson, and K. Lyytinen, "Research Commentary: The New Organizing Logic of Digital Innovation: An Agenda for Information Systems Research", Information Systems Research 21, 4 (2010), pp. 724-735.

[60] Boehm, B., "Get ready for agile methods, with care", Computer, 35, 1 (2002), pp. 64-69.

[61] Hevner, A. R., S. T. March, J. Park, and S. Ram, "Design Science in Information Systems Research", MIS Quarterly 28, 1 (2004), pp. 75-105. 